\title{
Coronary Sinus Atrial Septal Defect (Unroofed Coronary Sinus) with Total Anomalous Pulmonary Venous Connection-A Case Report
}

\author{
Ramachandran Muthiah \\ Thoothukudi Medical College Hospital, Thoothukudi, India \\ Email: cardioramachandran@yahoo.co.uk
}

How to cite this paper: Muthiah, R. (2017) Coronary Sinus Atrial Septal Defect (Unroofed Coronary Sinus) with Total Anomalous Pulmonary Venous Connection-A Case Report. Case Reports in Clinical Medicine, 6, 1-18.

http://dx.doi.org/10.4236/crcm.2017.61001

Received: November 14, 2016

Accepted: January 10, 2017

Published: January 13, 2017

Copyright $\odot 2017$ by author and Scientific Research Publishing Inc. This work is licensed under the Creative Commons Attribution International License (CC BY 4.0).

http://creativecommons.org/licenses/by/4.0/

\begin{abstract}
Introduction: To present a rare occurrence of coronary sinus atrial septal defect (ASD) associated with total anomalous pulmonary venous connection (TAPVC). Case Report: A 16-year-old girl was diagnosed with features of an atrial septal defect (ASD) by transthoracic echocardiography and the absence of PLSVC (persistent left superior vena cava) connection to coronary sinus was confirmed by saline contrast echocardiography ("bubble study"). Discussion: The cause of the dilated coronary sinus was due to total anomalous pulmonary venous connection. Conclusion: Coronary sinus atrial septal defect (ASD) is a rare interatrial shunt that is commonly associated with a persistent left superior vena cava (PLSVC) and occurs in less than $1 \%$ of cases of ASDs. It is characterized by the absence of at least a portion of the common wall that separates the coronary sinus and left atrium. Isolated defects are associated with low rate of morbidity and mortality.
\end{abstract}

\section{Keywords}

Ccoronary Sinus ASD, Raghib Complex, Bubble Study,

Total Anomalous Pulmonary Venous Connection (TAPVC)

\section{Introduction}

Coronary sinus is usually not dilated on echocardiography. Anomalous venous drainage into the coronary sinus either directly or through a persistent left superior vena cava (PLSVC) is one of the etiologies for a dilated coronary sinus [1]. Mild dilatation occurs in patients with poor left ventricular systolic function, greater dilatation in persistent LSVC and huge dilatation (Giant coronary sinus) occurs in PLSVC associated with absence of a right superior vena cava. The conditions associated with dilated coronary sinus are shown in Table 1 given. 
Table 1. Conditions associated with dilated coronary sinus.

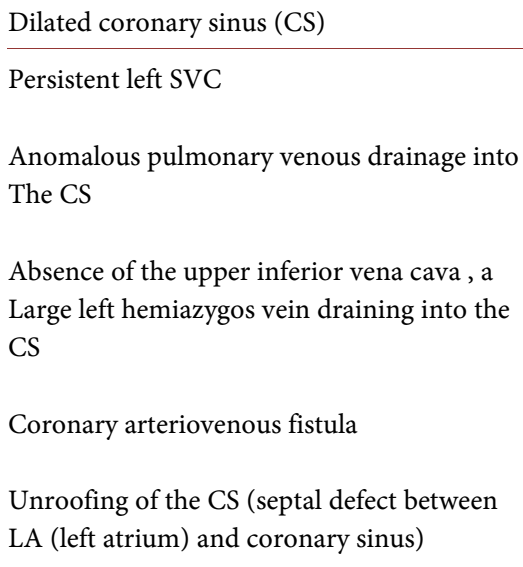

Coronary sinus ASDs are uncommon and so this case had been reported.

\section{Review of Literature}

Mantini's et al. proposed four categories of CS anomalies as enlarged CS, absent CS, atresia of the right atrial CS ostium and hypoplasia of the CS [2]. The enlarged CS category has two subtypes-subtype A (without left-to-right shunt) and subtype B (with left-to-right shunt). Mantini postulated that a connection between the LA and CS may serve to drain the CS in RA (right atrium) ostial stenosis. Eliot, et al. [3] described a fibrous band that narrowed the right atrial ostium of the CS. Scheller et al. presented a case of CS with two outlets, one to the RA, and the other to the LA [4].

Unroofed coronary sinus was first described by Raghib and colleagues in 1965 with the findings of left SVC drains into the left atrium, an ASD (which lies in the postero-inferior angle of the atrial septum and above the postero-medial commissure of the mitral valve and separated from the mitral valve by a small amount of septal tissue-the defect is considered as a true defect of a specific tissue) and absent coronary sinus which are collectively termed as "Raghib complex or syndrome" [5]. In unroofed coronary sinus, there is a direct CS to LA communication through a wall defect and the CS is usually enlarged.

Total anomalous pulmonary venous connection (TAPVC), a very unusual malformation of the heart was published by Philosophical Transactions of the Royal Society in London in 1798 [6]. It represents $2 \%$ of all congenital heart defects and 100 cases of anomalous pulmonary venous connections were reported in 1942 [7].

\section{Case Report}

A 16-year old girl was referred for echocardiographic evaluation with a history of exertional dyspnea and recurrent episodes of respiratory infection from childhood. Her pulse rate was $88 \mathrm{bpm}$ and blood pressure 110/70 mmHg. Physical examination revealed mild cyanosis and clubbing. Auscultation revealed grade $2 / 6$ soft systolic murmur in the left second intercostal space with a wide, 
fixed splitting of second heart sound. Ultrasound abdomen revealed normal liver and spleen. Blood chemistry revealed normal. ECG revealed right axis deviation and right bundle branch block (RBBB) pattern as shown in Figure 1. X-ray chest revealed increased pulmonary vascular markings with peripheral extension and a central prominence suggesting a left-to-right shunt at atrial level as shown in Figure 2. Transthoracic 2D echocardiography revealed an unroofed coronary sinus draining into the left atrium with anomalous pulmonary venous connection and an associated ostium secundum atrial septal defect (ASD) as shown in Figures 3-14. The girl was treated with antibiotics for the respiratory infection and advised early surgical correction.

\section{Discussion}

Coronary sinus is a systemic venous structure embryologically derived from the

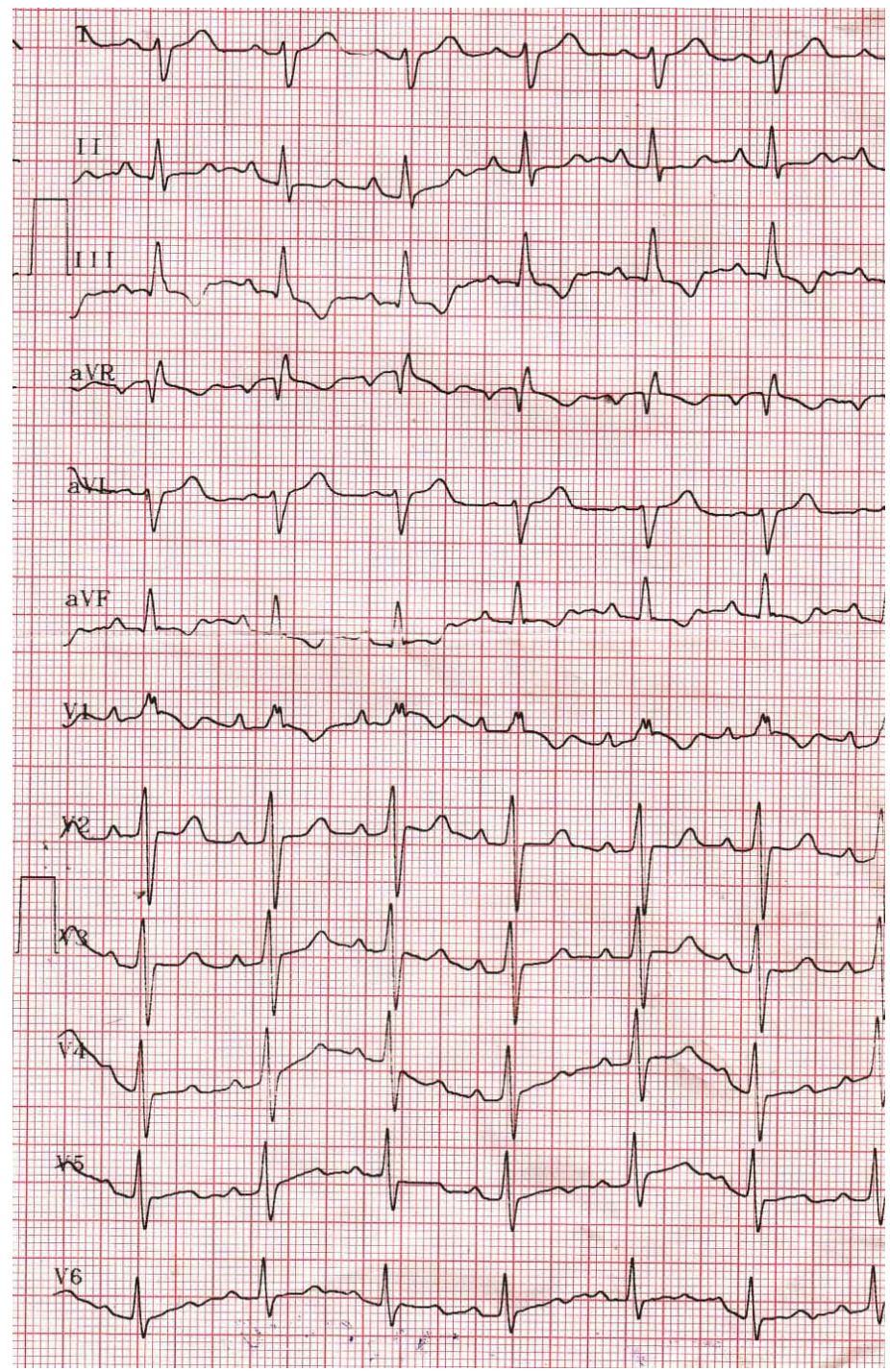

Figure 1. ECG revealed right axis deviation and right bundle branch block pattern in $\mathrm{V}_{1}$ suggesting a $\mathrm{RV}$ volume overload pattern of left-to-right shunt at atrial level. 


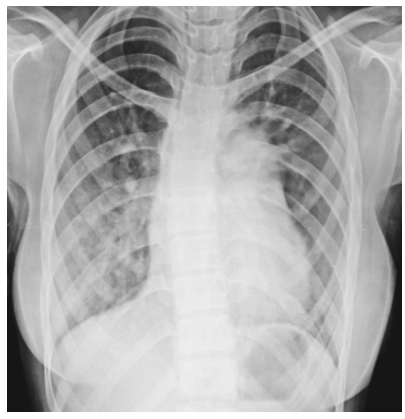

Figure 2. X-ray chest PA (posteroanterior view) revealed increased pulmonary vascular markings with a central prominence and peripheral extension suggesting a left-to-right shunt at atrial level.

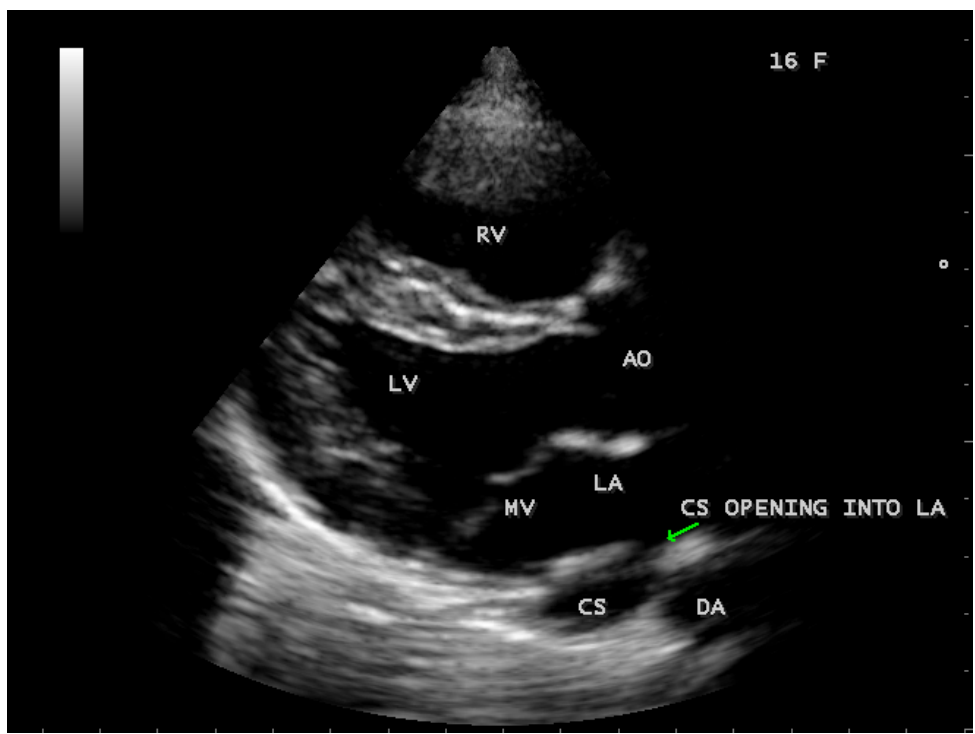

Figure 3. Parasternal long axis view showing the opening of coronary sinus into left atrium.

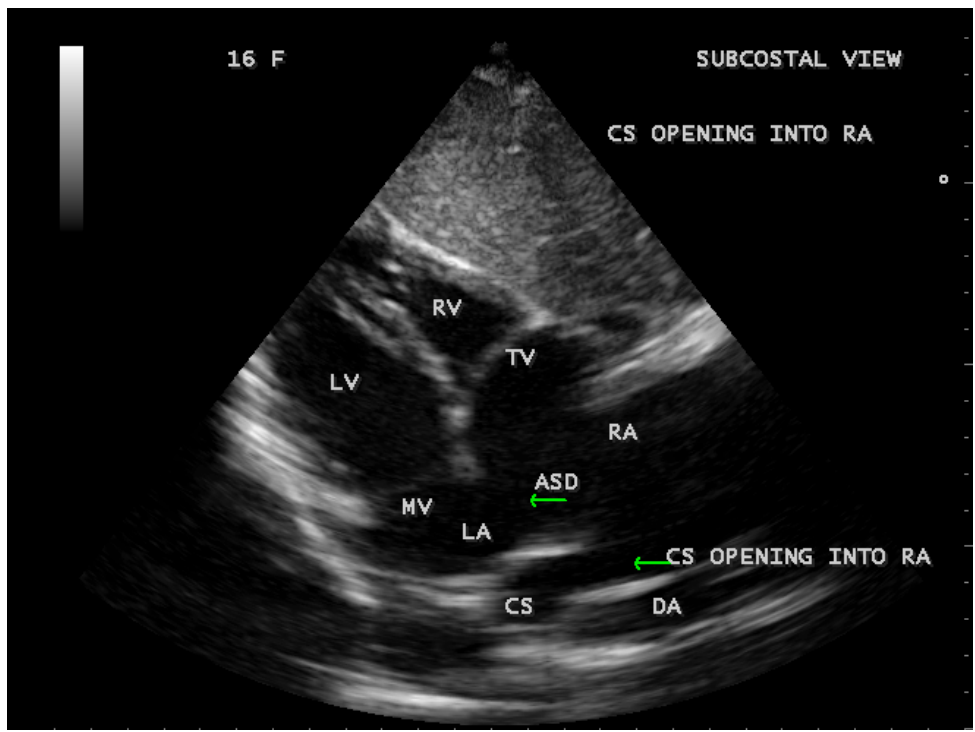

Figure 4. Subcostal view showing the opening of coronary sinus into the right atrium and ostium secundum atrial septal defect (ASD). 


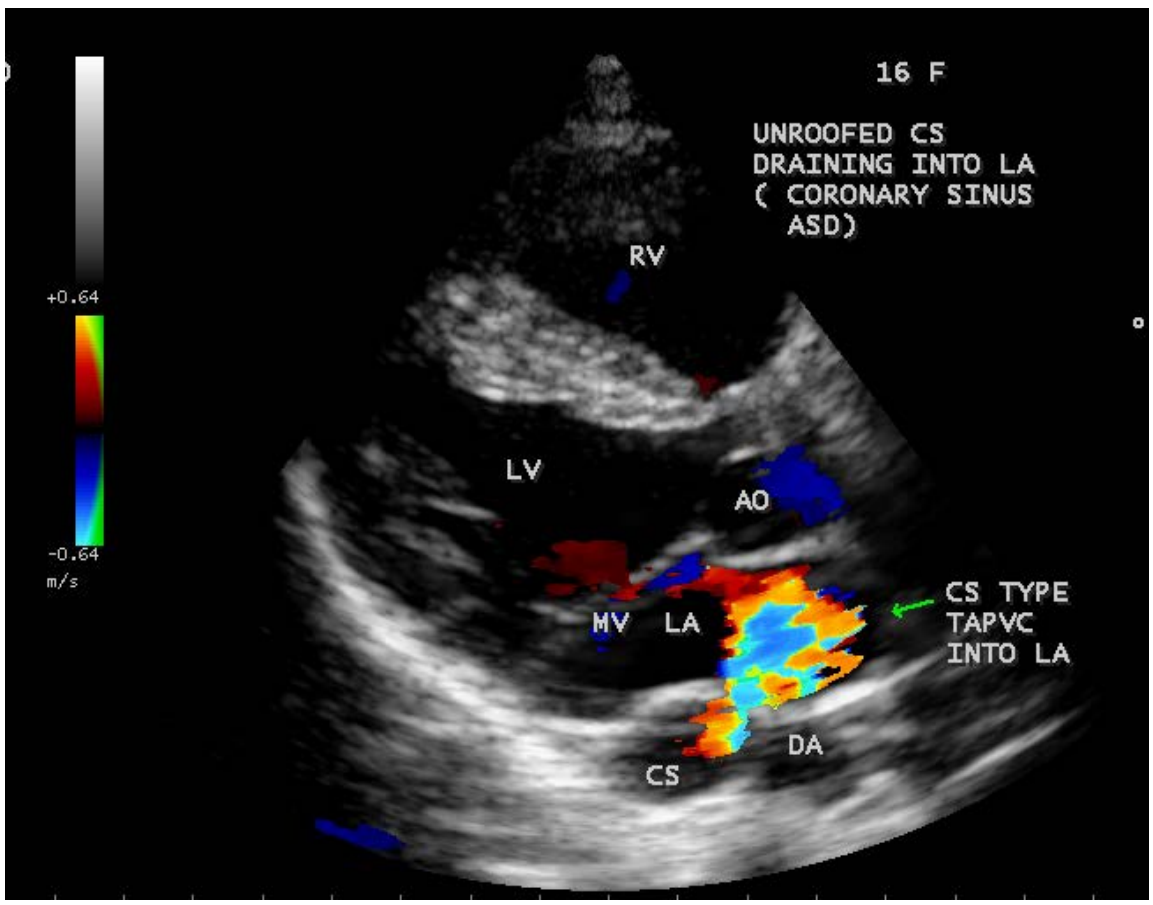

Figure 5. Parasternal long axis view showing the drainage of unroofed coronary sinus into the left atrium, constituting a right-to-left shunt-coronary sinus ASD (atrial septal defect) with total anomalous pulmonary venous connection (TAPVC).

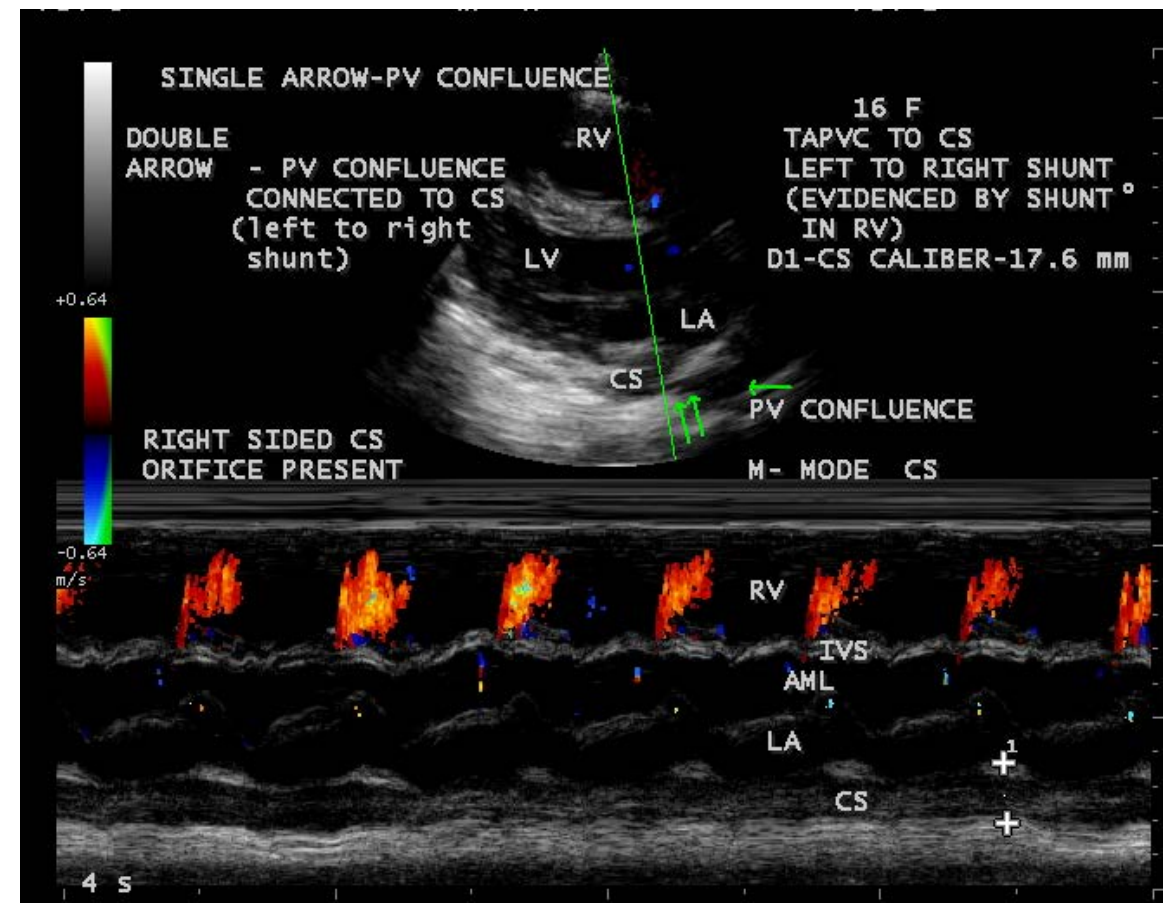

Figure 6. M-mode at CS (coronary sinus) level showing the shunting of blood into RV (right ventricle) from the coronary sinus and CS caliber- $17.6 \mathrm{~mm}$.

left common cardinal vein and normally drains into the right atrium. An 'unroofed coronary sinus' abnormally communicate with left atrium and called as "coronary sinus ASD (atrial septal defect)", in addition to draining the cardiac 


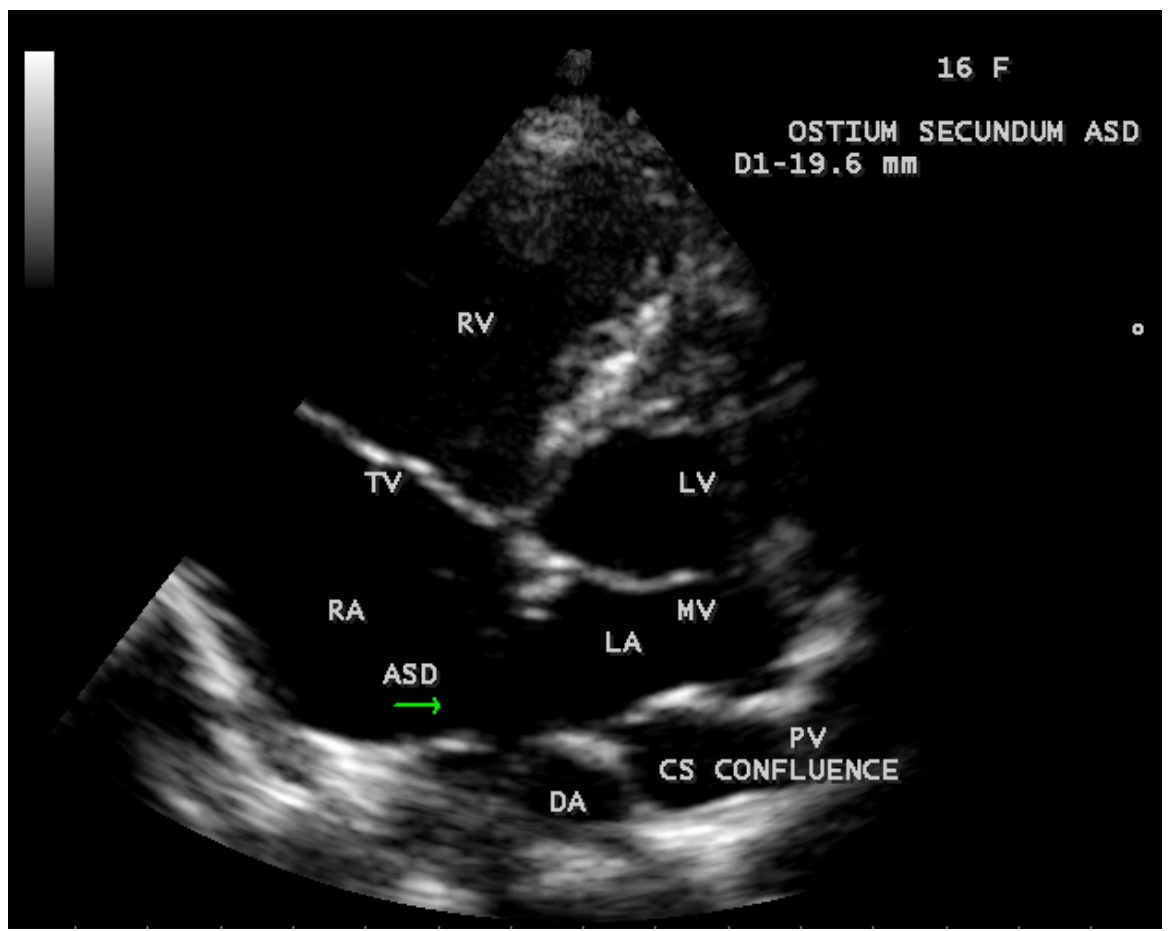

Figure 7. Showing the pulmonary venous confluence and ostium secundum ASD (atrial septal defect) in apical four chamber view (the size of secundum ASD is $19.6 \mathrm{~mm}$ ).

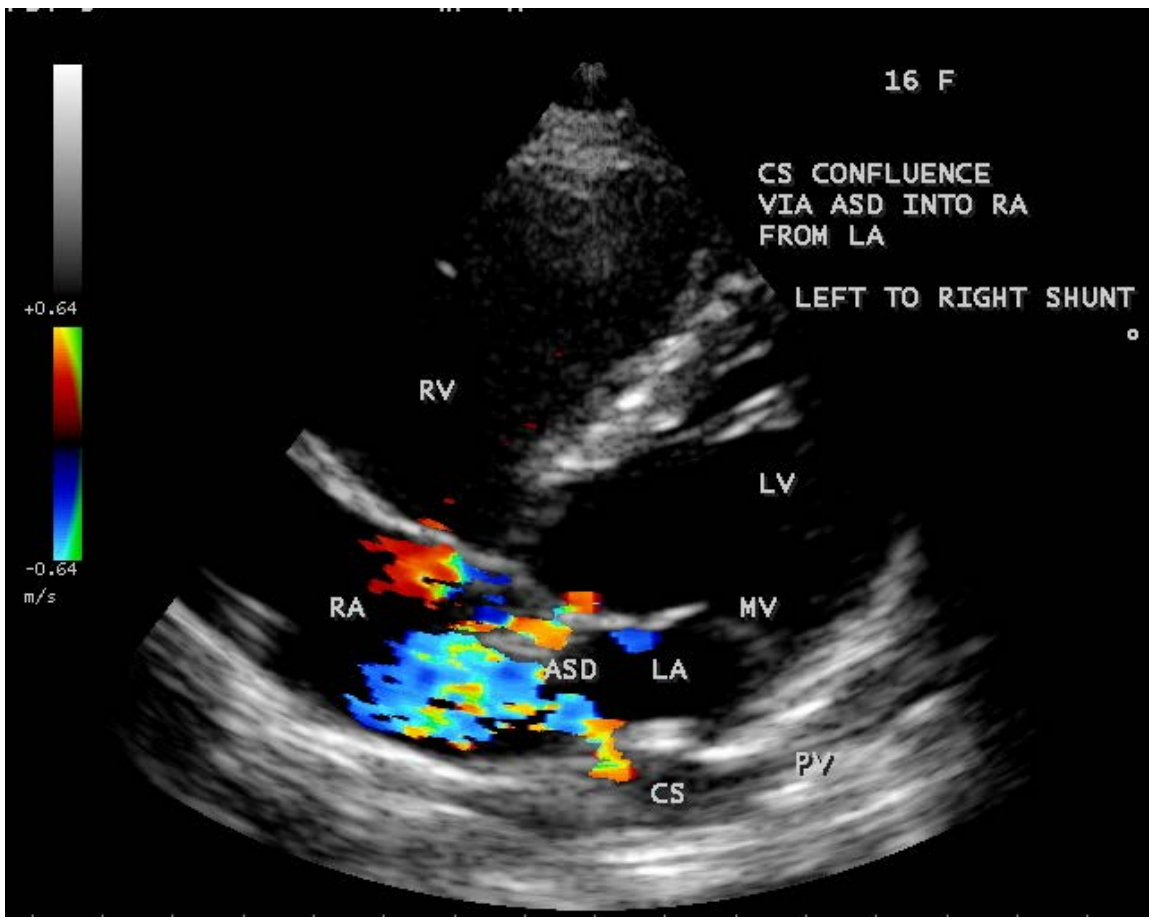

Figure 8. Tilted apical view showing the drainage of pulmonary venous confluence connected to coronary sinus (CS) into the right atrium through the secundum defect.

veins due to impaired development of partition between the left atrium and coronary sinus, i.e., subsequent dissolution of this partition [8], the roof coronary sinus either partially or completely. It results from imperfect or complete failure 


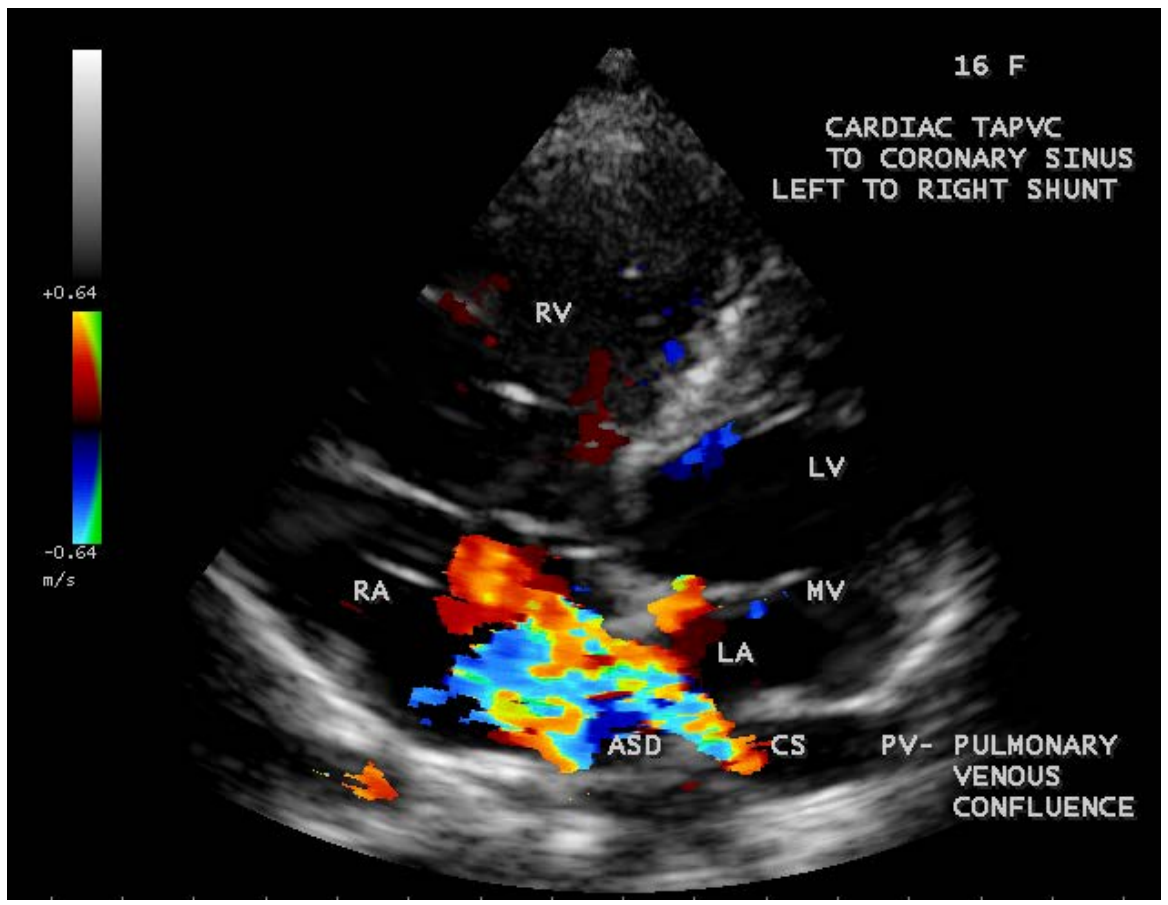

Figure 9. Tilted apical view showing the drainage of pulmonary venous confluence through ASD and constituting a left-to-right shunt.

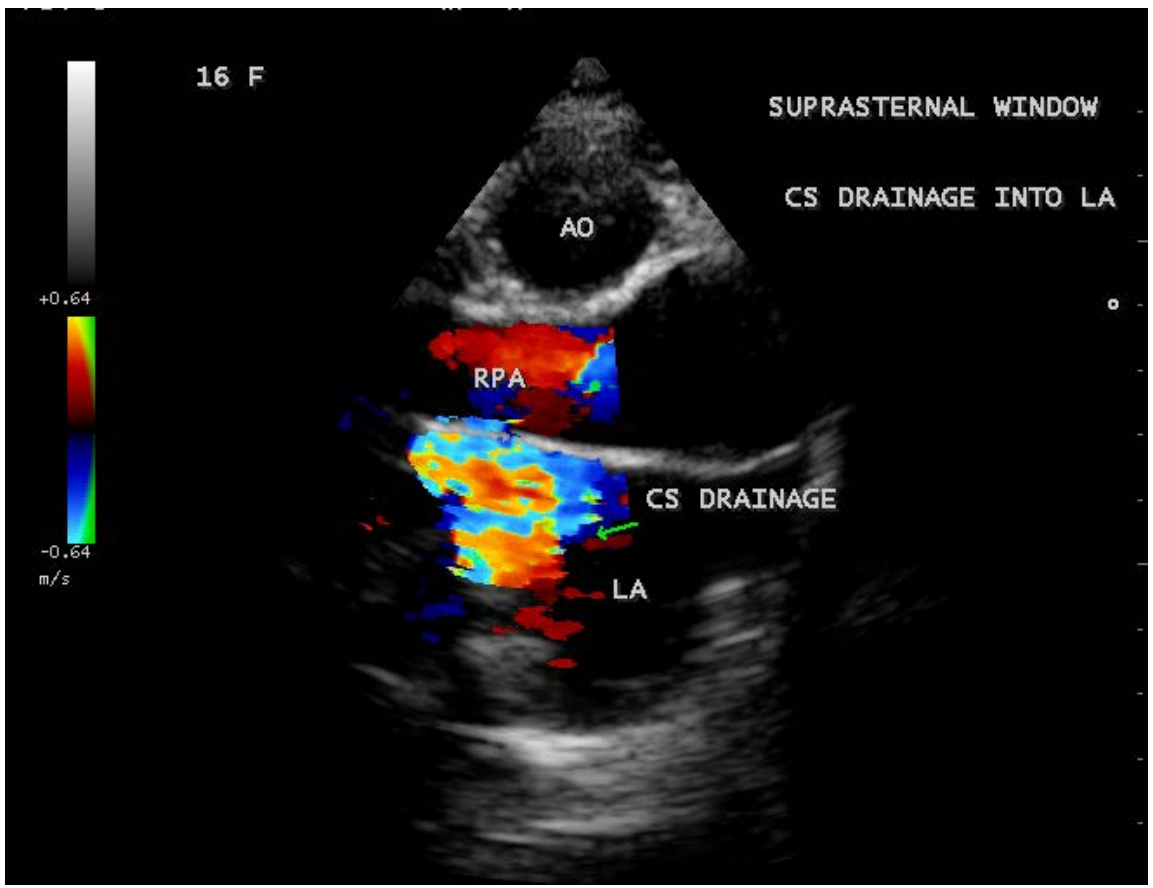

Figure 10. Suprasternal window showing the drainage of coronary sinus into left atrium (Coronary sinus ASD (atrial septal defect)).

of development of the left atriovenous fold and manifested as a focal (fenestration or partial unroofing) or complete absence of the coronary sinus septum. The fenestration into left atrium (LA) typically occurs between LA appendage and left upper pulmonary vein. Thus, coronary sinus ASDs are believed to arise 


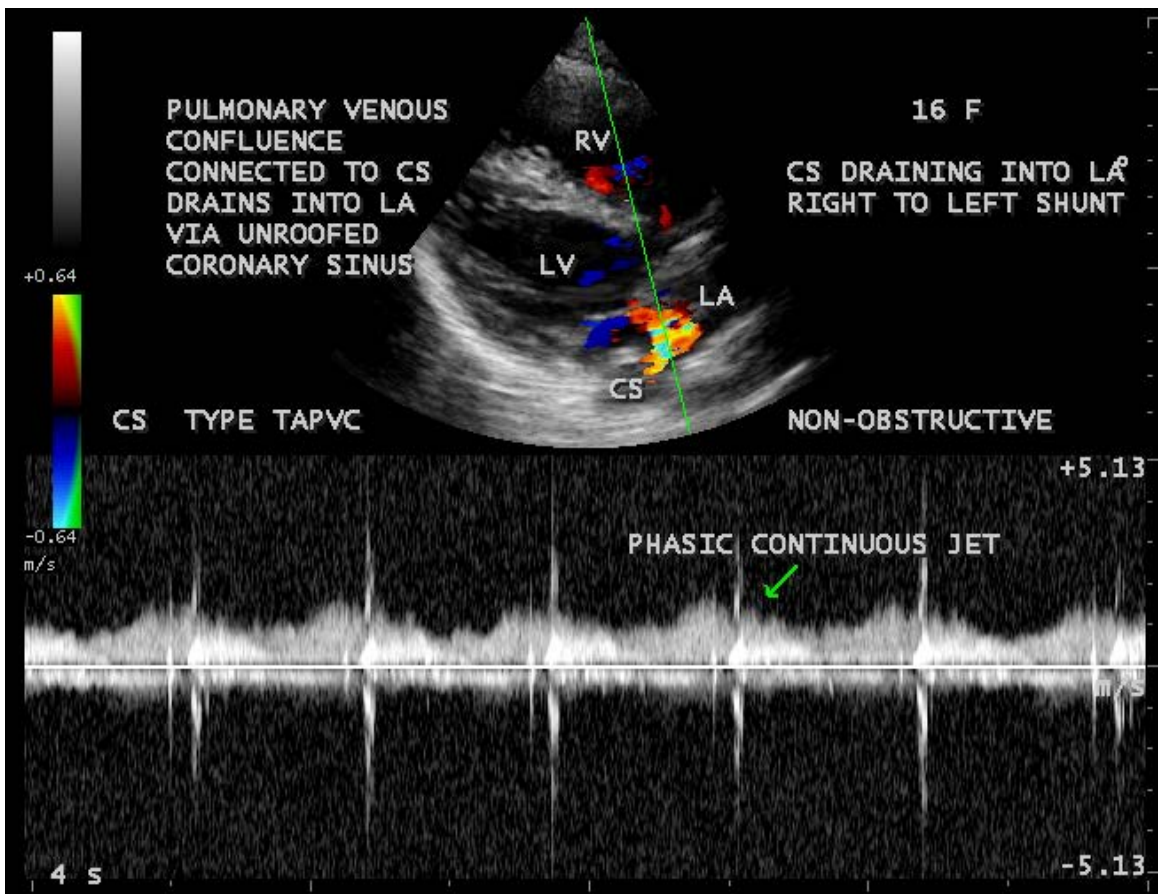

Figure 11. CW (Continuous Wave) Doppler showing the phasic continuous jet of pulmonary venous confluence connected to CS (coronary sinus)-non-obstructive type, draining into left atrium.

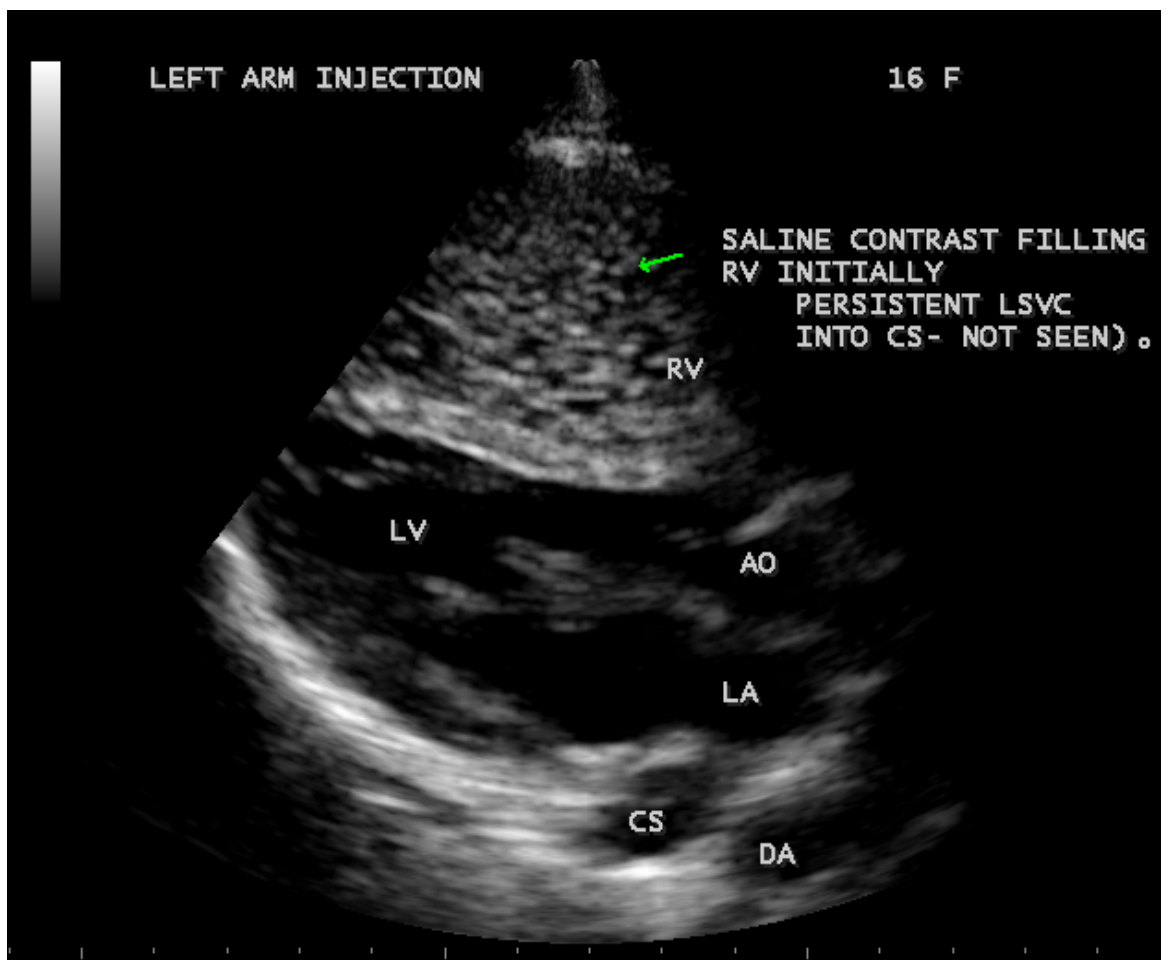

Figure 12. Bubble study showing the absence of persistent left superior vena cava (PLSVC) to coronary sinus by early appearance of saline contrast in the right ventricle (RV)-left arm injection (Parasternal long axis view). (Note: In PLSVC to CS, saline contrast appears earlier in CS (coronary sinus) than in the right sided cardiac chambers (RA (right atrium), RV (right ventricle)). 


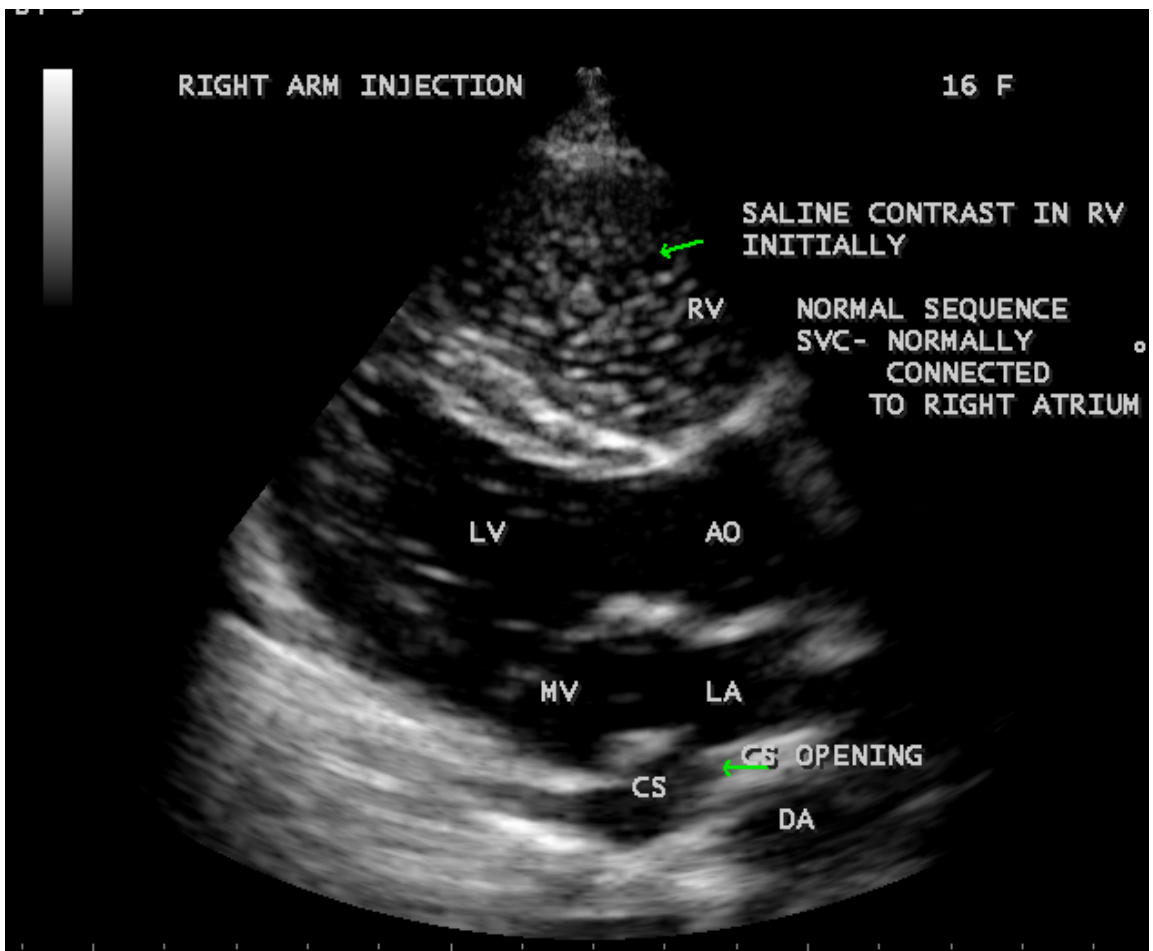

Figure 13. Bubble study showing the normal connection of right superior vena cava (RSVC) by early appearance of saline contrast in the right ventricle (RV)-right arm injection (Parasternal long axis view). (Note: If saline contrast appears earlier in CS than in the right-sided cardiac chambers (RA, RV), RSVC (right superior vena cava) is absent, PLSVC to CS is possible and the CS is aneurysmally dilated (giant CS).

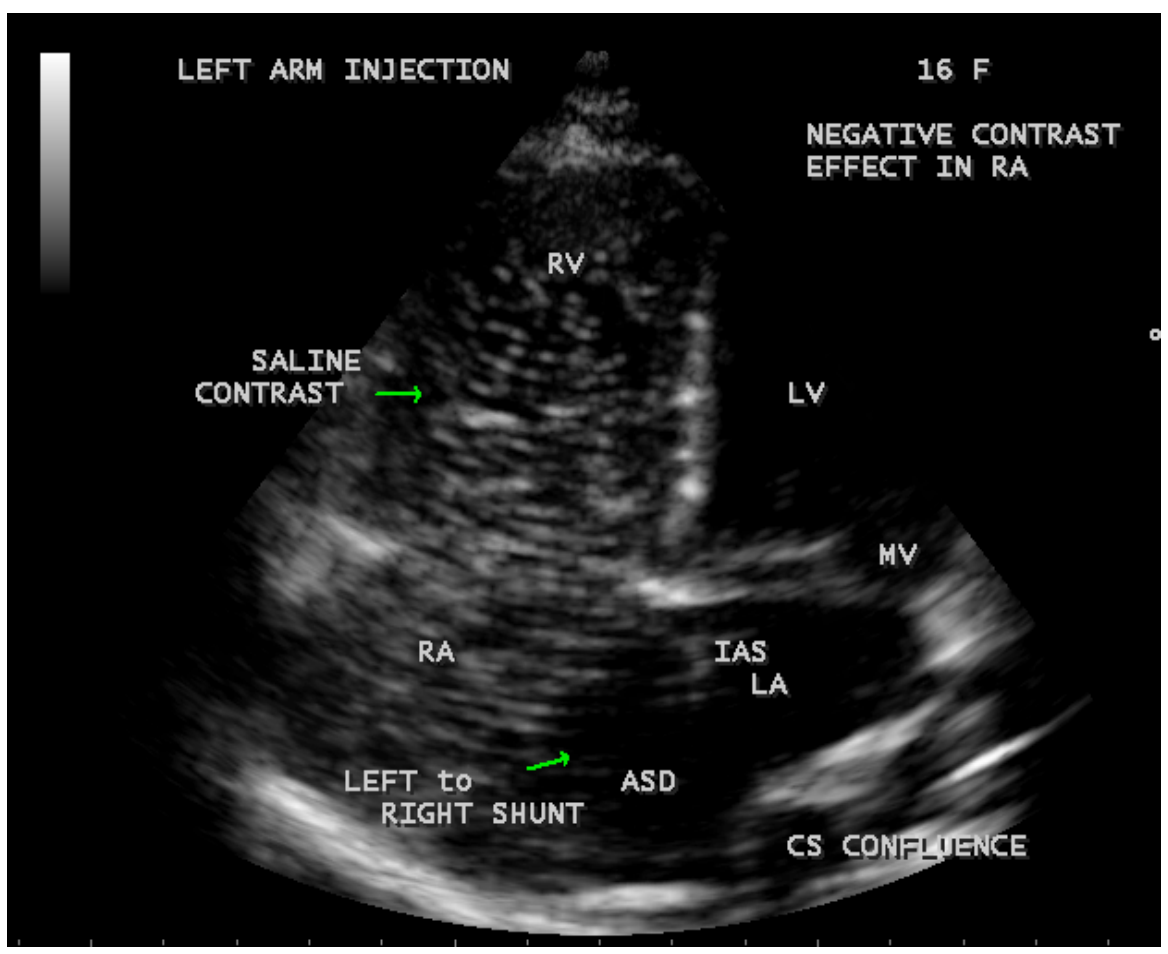

Figure 14. Bubble study showing the negative contrast effect in the right atrium due to left to right shunt through a secundum defect in apical four chamber view. 
from developmental failure of the wall between the left atrium and CS. It is the rarest type of atrial septal defect [9] [10] in which the anterior wall of coronary sinus was deficient and therefore allowed an interatrial communication [11]. The anatomic abnormality is variable and classified into four types by Kirklin and Barrat-Boys [12] as shown in Table 2.

No specific risk factors or known teratogens have been associated with coronary sinus ASDs. It may be observed most often in association with atrial situs abnormalities and heterotaxy syndromes with polysplenia or asplenia. No other genetic syndromes are known to be associated with coronary sinus ASDs.

In TAPVC (total anomalous pulmonary venous connection), the pulmonary veins connect directly to the systemic venous circulation via persistent splanchnic connections and results from the failure of the transfer of pulmonary venous drainage from the splanchnic plexus to the left atrium in the normal developmental sequence. Four types have been described as supracardiac, cardiac, infracardiac and mixed by Darling et al. [13]. Cardiac type TAPVC occurs in $25 \%$ of cases in which the pulmonary venous confluence drains into the coronary sinus or directly to the right atrium.

\subsection{Echocardiographic Features}

Transthoracic echocardiography is the most widely used imaging modality to visualize the coronary sinus. In parasternal long axis view, the coronary sinus is represented by a small sonolucency at the posterior left atrioventricular (AV) junction and moving with cardiac motion. In this view, the coronary sinus is anterior to and quite separate from the larger, the more posterior sonolucency of the descending thoracic aorta as shown in Figure 3 which is fixed and not move with cardiac motion. It has been suggested that there is a symmetric distension of coronary sinus in elevated right heart pressures and in persistent LSVC, it maintains its oval shape with an eccentricity index of $<0.8$ [14]. The normal CS caliber is $8.7 \pm 2.5 \mathrm{~mm}$. In this patient, the CS is dilated and its caliber was 17.6 $\mathrm{mm}$ as shown in Figure 6. The dilated coronary sinus is sometimes the initial echocardiographic abnormality detected and this finding should always prompt a search for anomalous pulmonary venous drainage. Dilated coronary sinus is the most common echocardiographic finding of a PLSVC and the diagnosis is then confirmed by saline contrast echocardiography ("bubble study").

After agitated saline injection into a left-sided brachial vein, bubble contrast appears in the right ventricle as shown in Figure 12, suggesting the absence of PLSVC draining to coronary sinus. When agitated saline is injected into a rightsided brachial vein, the echo contrast enhances the right ventricle before the CS,

Table 2. Types of unroofed coronary sinus.

\begin{tabular}{cc}
\hline Type I & Completely unroofed with LSVC \\
Type II & Completely unroofed without LSVC \\
Type III & Partially unroofed midportion \\
Type IV & Partially unroofed terminal portion \\
\hline
\end{tabular}


thus confirming a normal right SVC [15] as shown in Figure 13. A negative contrast effect in the right atrium as shown in Figure 14 indicates a left-to-right shunt via secundum defect [16]. An unroofed coronary sinus draining into the left atrium (right-to-left shunt) was shown in Figure 5 and M-mode at CS level revealed the normal orifice of CS at right side (as evidenced by shunting of blood into RV-left to right shunt due to connection of pulmonary venous confluence to $\mathrm{CS}$ ) as shown in Figure 6.

Most children with isolated coronary sinus defects are asymptomatic. The size of the defect and the degree of shunting determine the symptoms similar to the other types of ASDs. Pulmonary venous obstruction may occur in all types of anomalous connections and in cardiac type, obstruction seldom develops, but may occur at the junction of common pulmonary vein to the coronary sinus. Obstructive TAPVC may present with pulmonary edema or severe hypercyanotic episodes and it is more common in infradiaphragmatic type. A continuous non-phasic pulmonary venous flow is characteristic of obstruction in TAPVC. In this case, the continuous flow is phasic as shown in Figure 11 suggesting a non-obstructive flow pattern.

\subsection{Management}

\subsubsection{Medical Therapy}

No specific medical therapy is necessary and Intervention is not required in asymptomatic patients.

In patients with TAPVC to coronary sinus, if pulmonary venous obstruction occurs, the hypercyanotic episodes are treated with pulmonary vasodilators such as inhaled nitric oxide, lower-dose magnesium sulphate and PGE $_{1}$ (Prostaglandin $E_{1}$-alprostadil IV). Pulmonary edema is best treated with surgical relief of obstruction, but diuretics, assisted ventilation with high fraction of inspired oxygen $\left(\mathrm{FIO}_{2}\right)$ and end-expiratory pressure are often helpful.

\subsubsection{Catheter Therapy}

Transcatheter device closure is not considered a feasible option for coronary sinus ASDs due to its proximity to tricuspid valve and conduction system and a lack of adequate tissue rim for device seating [17]. Klijima et al. reported success in two cases and the orifice of coronary sinus was closed using the Amplatzer septal occluder without any complications in isolated defects [18]. Successful closure is possible in small coronary ASDs [19]. However, St. Jude Medical's Amplatzer atrial septal occluder may cause tissue erosion and leads to problems such as cardiac tamponade.

No catheter-corrective therapy is possible for TAPVC (total anomalous pulmonary venous connection).

\subsubsection{Surgical Therapy}

Surgical closure in childhood is recommended for CS-ASDs similar to secundum defects. Indication for surgery in small defects are controversial, but the risk of paradoxical embolism and cryptogenic stroke remains. Severe pulmonary 
hypertension (pulmonary vascular resistance (PVR) $>15$ Wood units is a contraindication for surgical repair.

Surgical treatment is complicated by its proximity to AV node and sutures must be placed close to the superior rim of the defect and therefore patch repair (pericardial patch or bioprosthetic material) is recommended. The mortality from surgical closure of coronary sinus ASDs appear to be low [20].

In TAPVC, the goal of surgery is to redirect pulmonary vein flow to the left atrium. In cardiac connection (to coronary sinus), the atrial septum is resected partially and a new septum is surgically created, directing pulmonary veins to the left atrium. The coronary sinus may be separately tunneled to the right atrium or left to drain with pulmonary veins to the left atrium which may be preferred in this girl.

\subsection{Screening of Population}

A SVC (superior vena cava) type total anomalous pulmonary venous connection (TAPVC) was found by echocardiographic imaging in a 6-year old girl as shown in Figure 15 and Figure 16 and the right atrium is grossly dilated. A coronary sinus ASD with TAPVC was detected in a newborn as shown in Figures 17-22 and the right atrium is not much dilated as in Figure 15 and Figure 16.

\section{Conclusion}

Coronary sinus ASD is a rare congenital anomaly which might be difficult to di-

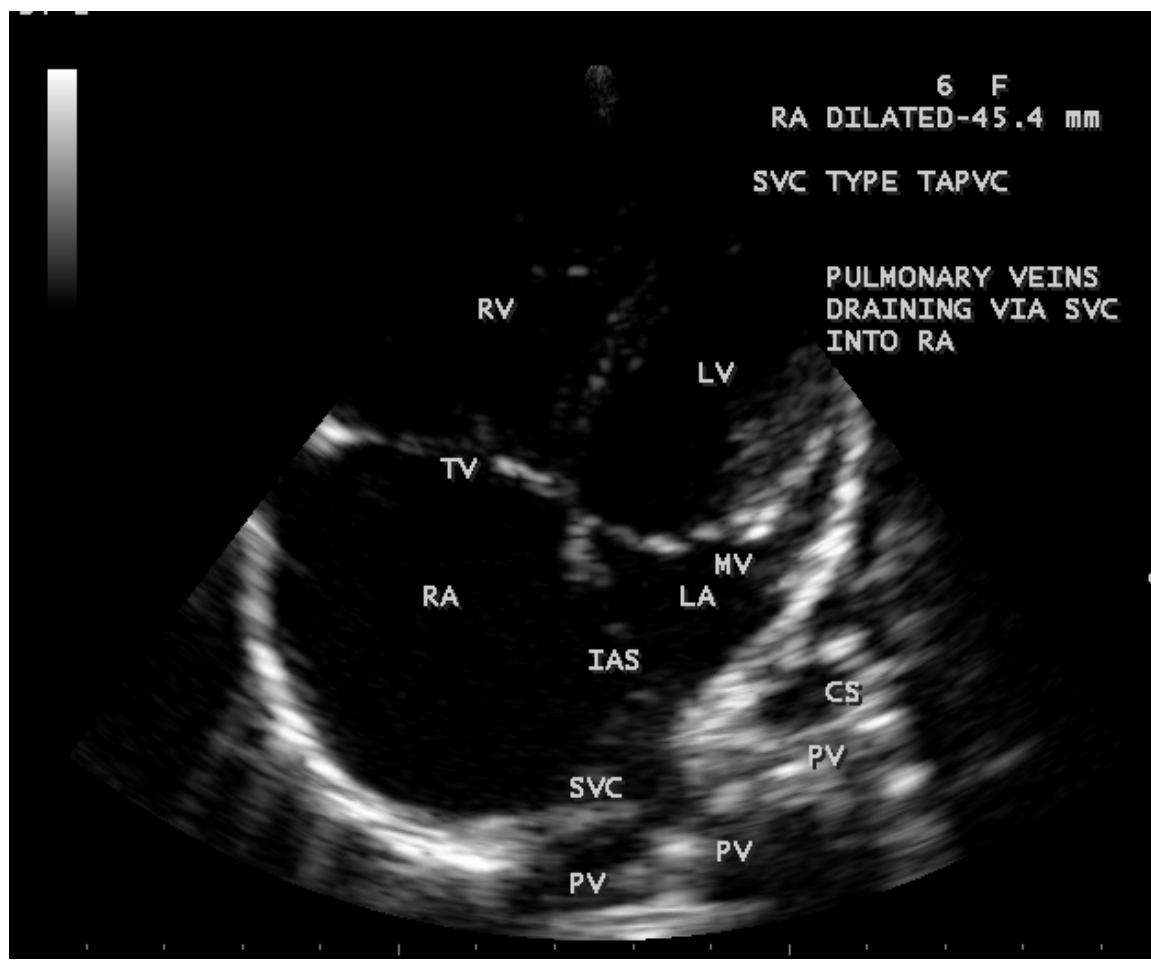

Figure 15. SVC (superior vena cava) type total anamolous pulmonary venous connection (TAPVC)-Apical four chamber view in a 6-year old girl. Right atrium (RA) dilated$45.4 \mathrm{~mm}$ 


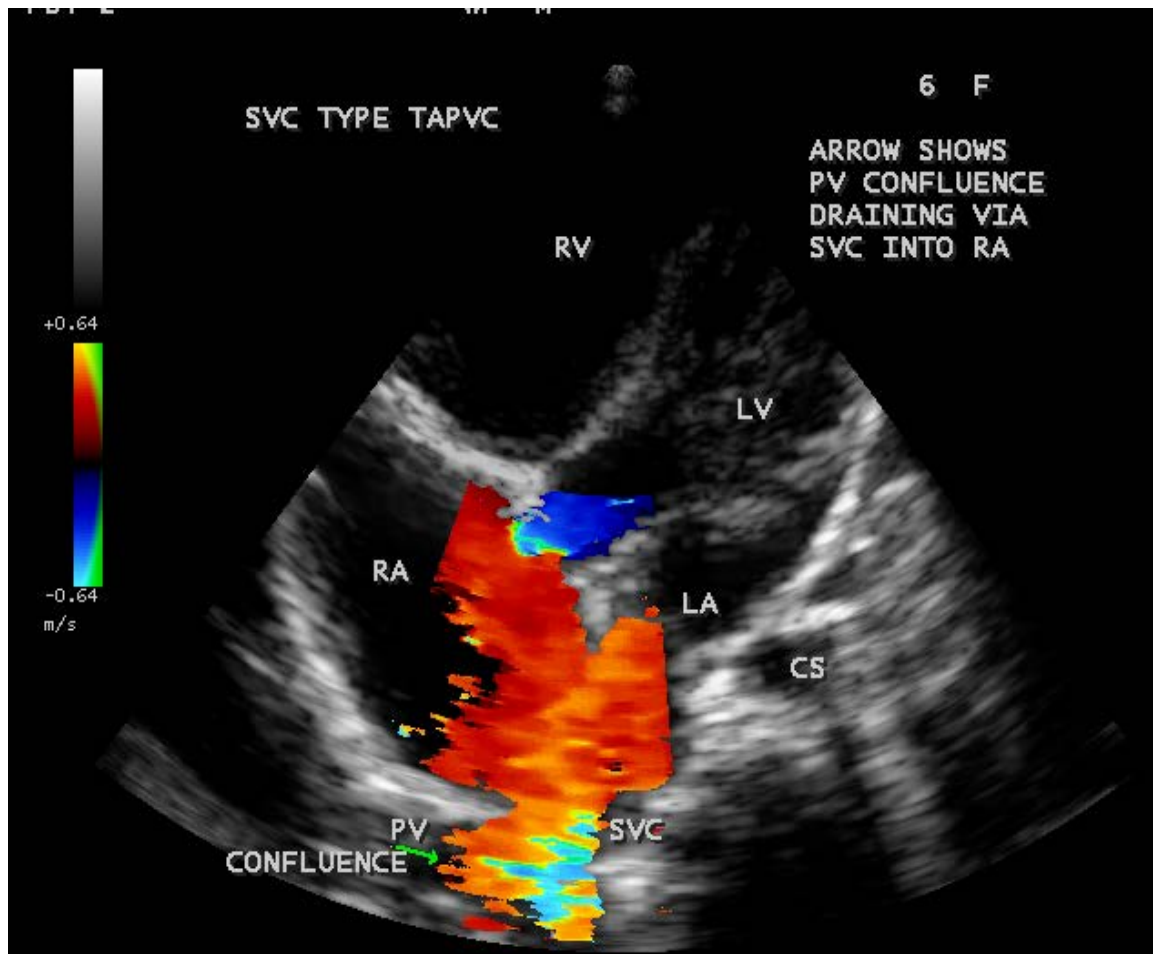

Figure 16. Color flow imaging showing the SVC (superior vena cava) type total anomalous pulmonary venous connection (TAPVC) in a 6-year old girl in apical four chamber view.

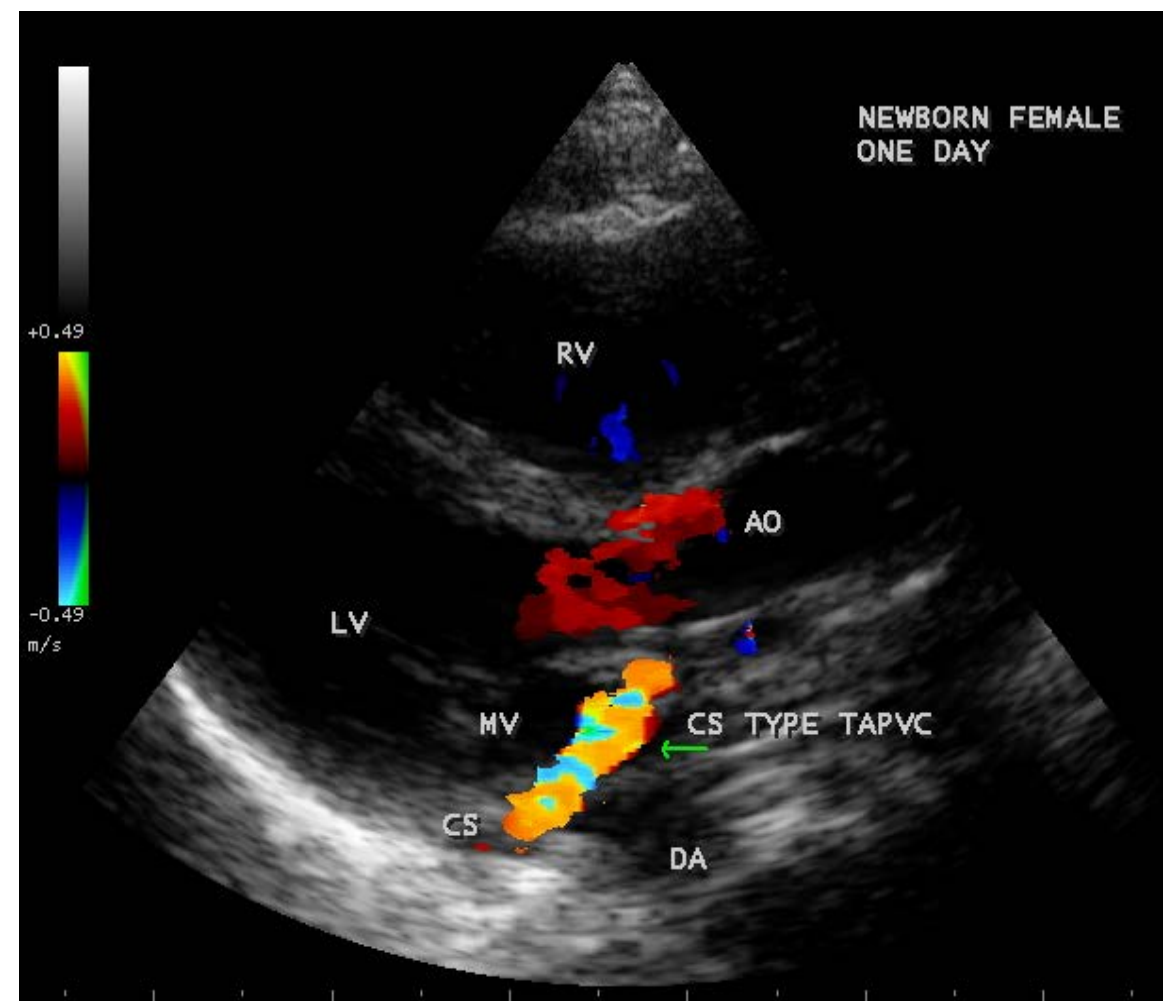

Figure 17. Parasternal long axis view showing the coronary sinus ASD (atrial septal defect) with total anomalous pulmonary venous connection (CS type TAPVC) in a new born. 


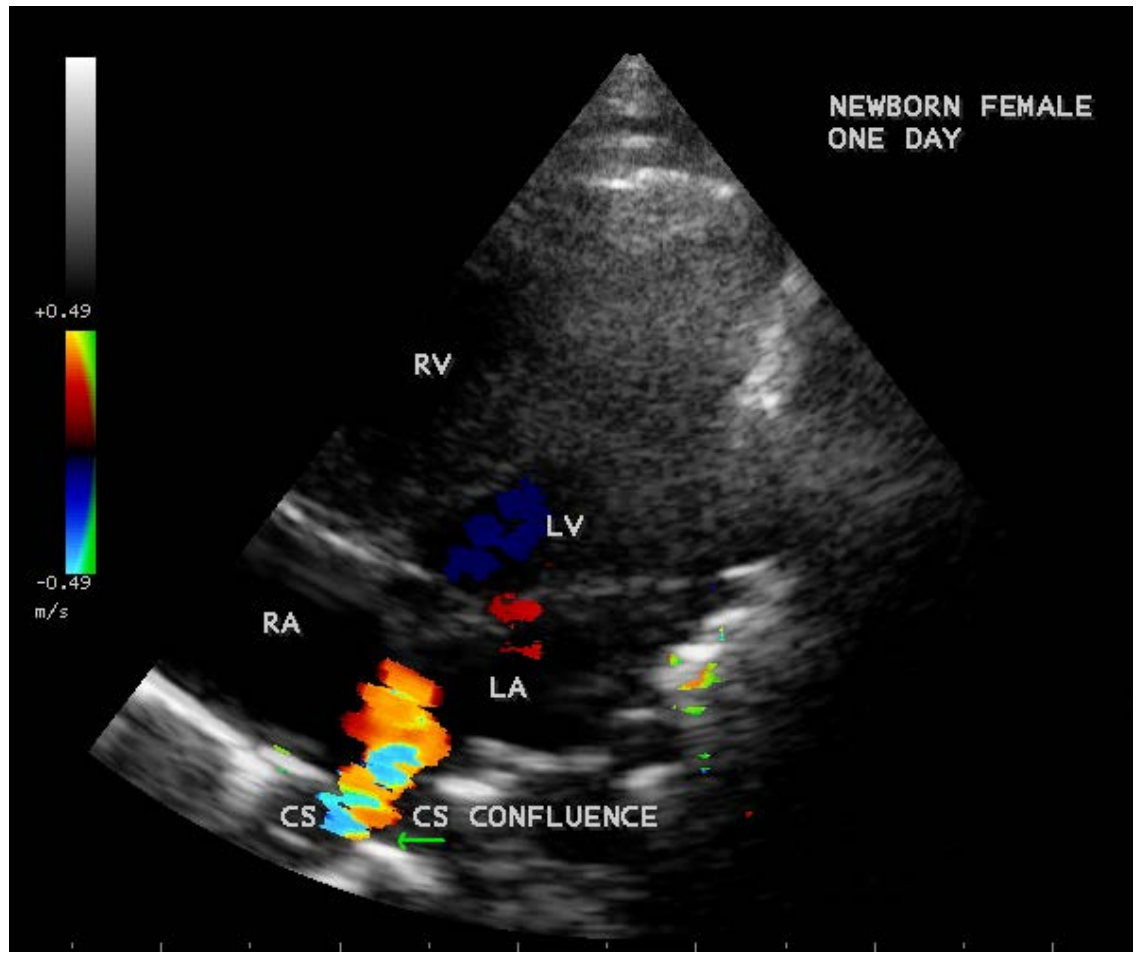

Figure 18. Tilted apical view showing the CS confluence in a newborn.

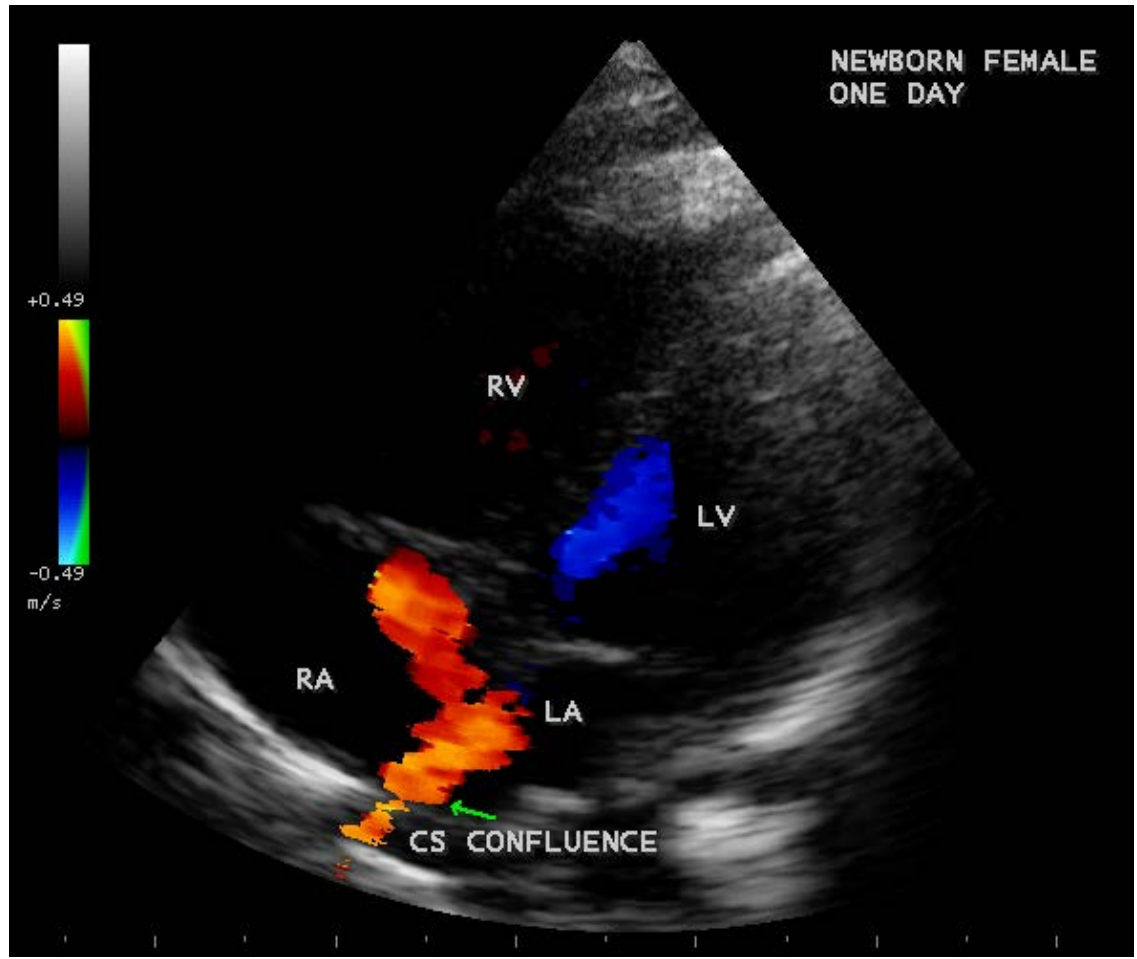

Figure 19. Tilted apical view showing the drainage of CS confluence into Left atrium (LA) in apical four chamber view in a newborn.

agnose [21] and it has been observed in patients with isolated secundum ASD [22]. A coronary sinus defect without an associated PLSVC (persistent left superior vena cava) is rare. It is not a true defect of the atrial septum [23] and its 


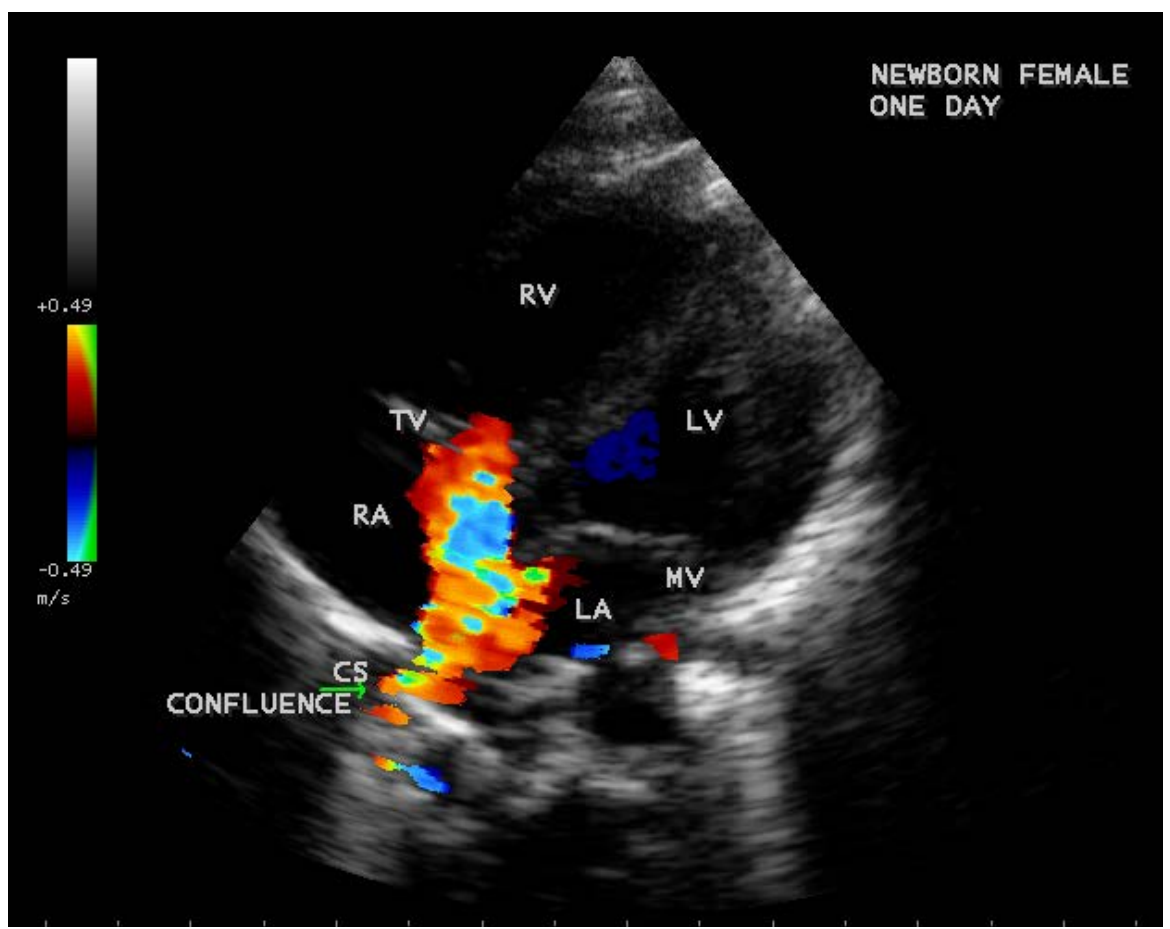

Figure 20. Tilted apical view-Color flow imaging showing the CS confluence jet mimicking as superior vena cava type total anomalous pulmonary venous connection (SVC type TAPVC) in a newborn.

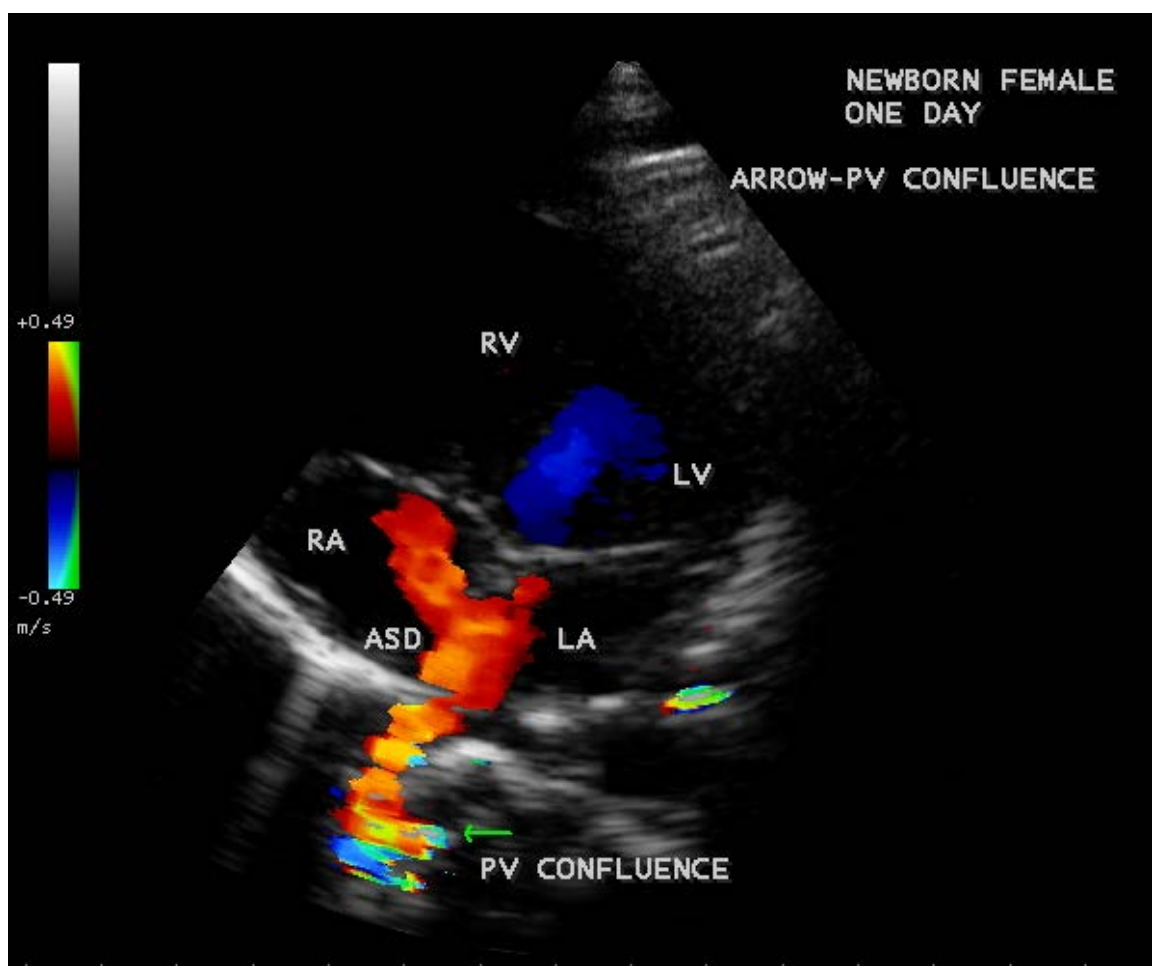

Figure 21. Apical four chamber view showing the coronary sinus type total anomalous pulmonary venous connection in a newborn and a secundum ASD (atrial septal defect). Right atrium (RA) is not dilated and thus differentiated from superior vena cava type total anomalous pulmonary venous connection (SVC type TAPVC) as shown in Figure 15 and Figure 16 in which the right atrium is grossly dilated. 


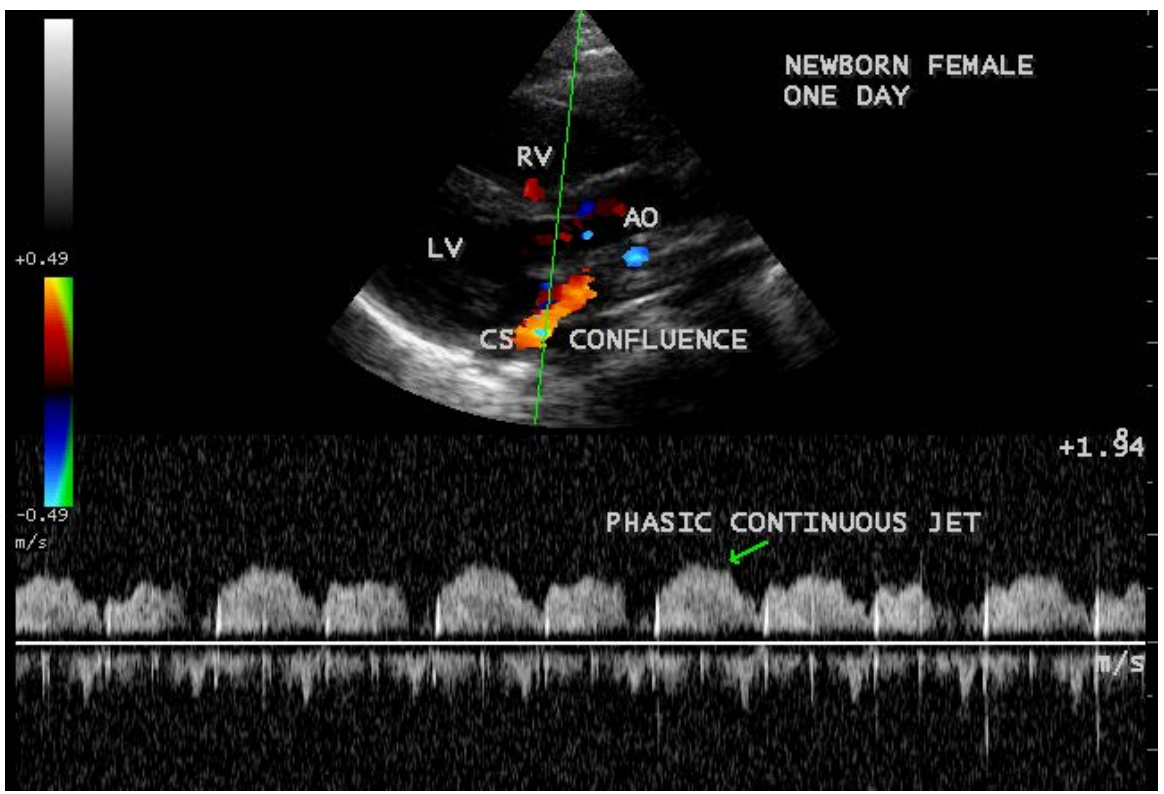

Figure 22. CW (Continuous Wave) Doppler Showing the phasic continuous jet of CS (coronary sinus) confluence in a newborn.

physiology is similar to other ASDs. Interatrial communication is through the mouth of the coronary sinus, which is located below and posterior to the fossa ovale and Imaging plays a crucial role in the diagnosis. A coronary sinus with partially unroofed terminal portion (Type IV) was found by transthoracic echocardiography, it is dilated due to total anomalous pulmonary venous connection (TAPVC) rather than PLSVC and constituting a cardiac type TAPVC to coronary sinus in a 16-year old girl.

\section{References}

[1] Weyman, A.E. (1994) Left Ventricular Inflow Tract II: The Left Atrium, Pulmonary Veins, and Coronary Sinus. In: Principles and Practice of Echocardiography. 2nd Edition, Lea \& Febiger, Philadelphia, 491.

[2] Mantini, E.G.C., Lillehei, C.W. and Edwards, J.E. (1966) Congenital Anomalies Involving the Coronary Sinus. Circulation, 33, 317-327. https://doi.org/10.1161/01.CIR.33.2.317

[3] Eliot, R.S., Wang, Y., Elliott, L.P., Varco, R.L. and Edwards, J.E. (1963) Clinical Pathologic Conference. American Heart Journal, 66, 542-551.

https://doi.org/10.1016/0002-8703(63)90388-0

[4] Scheller, V., Mazur, W., Kong, J. and Chung, E.S. (2009) Coronary Sinus to Left Atrial Communication. Case Reports in Medicine, 2009, Article ID: 790715. https://doi.org/10.1155/2009/790715

[5] Raghib, G., Ruttenberg, H.D., Anderson, R.C., Amplatz, K., Adams Jr., P., Edwards, J.E. (1965) Termination of Left Superior Vena Cava in Left Atrium, Atrial Septal Defect, and Absence of Coronary Sinus: A Developmental Complex. Circulation, 31, 906-918. https://doi.org/10.1161/01.CIR.31.6.906

[6] Wilson, J. (1798) A Description of the Very Unusual Formation of the Human Heart. Philosophical Transactions of the Royal Society of London, 88, 346.

https://doi.org/10.1098/rstl.1798.0014 
[7] Brody, H. (1942) Drainage of Pulmonary Veins into the Right Side of the Heart. Archives of Pathology \& Laboratory Medicine, 33, 221.

[8] Knauth, A., McCarthy, K.P., Webb, S., Ho, S.Y., Allwork, S.P., Cook, A.C., et al. (2002) Interatrial Communication Through the Mouth of the Coronary Sinus. Cardiology in the Young, 12, 364-372. https://doi.org/10.1017/S104795110001297X

[9] Ootaki, Y., Yamaguchi, M., Yoshimura, N., Oka, S., Yoshida, M. and Hasegawa, T. (2003) Unroofed Coronary Sinus Syndrome: Diagnosis, Classification and Surgical Treatment. The Journal of Thoracic And Cardiovascular Surgery, 126, 1655-1656. https://doi.org/10.1016/S0022-5223(03)01019-5

[10] Yeager, S., Chin, A. and Sanders, S. (1984) Subxiphoid Two-Dimensional Echocardiographic Diagnosis of Coronary Sinus Septal Defects. American Journal of Cardiology, 54, 686-687. https://doi.org/10.1016/0002-9149(84)90282-0

[11] Gould, S.E. (1960) Raghib Complex: Pathology of the Heart. 2nd Edition, Charles C. Thomas, Spring Field, 275. Echocardiography Journal.

[12] Kirklin, J. and Barrat-Boys, B.G. (1986) Cardiac Surgery. John Wiley and Sons, New York.

[13] Craig, J.M., Darling, R.C. and Rothney, W.B. (1957) Total Pulmonary Venous Drainage into the Right Side of the Heart; Report of 17 Autopsied Cases Not Associated With Other Major Cardiovascular Anomalies. Laboratory Investigation, 6, 44-64.

[14] Kolski, B.C., Khadivi, B., Anawati, M., et al. (2011) The Dilated Coronary Sinus: The Utility of Coronary Sinus Cross Sectional Area And Eccentricity Index in Differentiating Right Atrial Pressure Overload From Persistent Left Superior Vena Cava. Echocardiography, 28, 829-832. https://doi.org/10.1111/j.1540-8175.2011.01445.x

[15] Dearstine, M., Taylor, W. and Kerut, E.K. (2000) Persistent Left Superior Vena Cava, Chest X-Ray and Echocardiographic Findings. Echocardiography, 17, 453-455. https://doi.org/10.1111/j.1540-8175.2000.tb01164.x

[16] Feigenbaum, H., Armstrong, W.F. and Ryan, T. (2005) Congenital Heart Diseases, Feigenbaum's Echocardiography. 6th Edition, Lippincott Williams \& Wilkins, Philadelphia, Chapter 18, Figure 18.51 A, 588.

[17] Wang, J.K., Chen, S.J., Hsu, J.Y., et al. (2014) Midterm Follow-Up Results of Transcatheter Treatment in Patients with Unroofed Coronary Sinus. Catheterization and Cardiovascular Interventions, 83, 243-249.

[18] Klijima, Y., Taniguchi, M. and Akagi, T. (2011) Catheter Closure of Coronary Sinus Atrial Septal Defect Using Amplatzer Septal Occluder. Cardiology in the Young, 22, 223-226.

[19] Di Bernardo, S., Fasnacht, M. and Berger, F. (2003) Transcatheter Closure of a Coronary Sinus Defect with an Amplatzer Septal Occluder. Catheterization and Cardiovascular Interventions, 60, 287-290.

[20] Jost, A., Connolly, C.H., Danielson, M., Dearani, G.K., Wames, J.A., Jamil, C.A. and Tajik, A. (2007) Clinical Features and Surgical Outcome in 25 Patients with Fenestrations of the Coronary Sinus. Cardiology in the Young, 17, 592-600.

[21] Ngee, T., Lim, M.C., de Laarazabal, C. and Sundaram, R.D. (2011) Unroofed Coronary Sinus Defect. Journal of Computer Assisted Tomography, 35, 246-247. https://doi.org/10.1097/RCT.0b013e31820828c2

[22] Freedom, R.M., Culham, J.A.G. and Rowe, R.D. (1981) Left Atrial to Coronary Sinus Fenestration (Partially Unroofed Coronary Sinus): Morphologic and Angiocar- 
diographic Observations. British Heart Journal, 46, 63-68.

https://doi.org/10.1136/hrt.46.1.63

[23] Martin, S.S., Shapiro, E.P. and Mukherjee, M. (2014) Atrial Septal Defects. Clinical Manifestations, Echo Assessment, and Intervention. Clinical Medicine Insights Cardiology, 8, 93-98.

Submit or recommend next manuscript to SCIRP and we will provide best service for you:

Accepting pre-submission inquiries through Email, Facebook, LinkedIn, Twitter, etc. A wide selection of journals (inclusive of 9 subjects, more than 200 journals)

Providing 24-hour high-quality service

User-friendly online submission system

Fair and swift peer-review system

Efficient typesetting and proofreading procedure

Display of the result of downloads and visits, as well as the number of cited articles Maximum dissemination of your research work

Submit your manuscript at: http://papersubmission.scirp.org/

Or contact crcm@scirp.org 